\title{
LIII. On a peculiarity of the normal component of the attraction due to certain surface distributions
}

\author{
Ganesh Prasad M.A. D.Sc.
}

To cite this article: Ganesh Prasad M.A. D.Sc. (1918) LIII. On a peculiarity of the normal component of the attraction due to certain surface distributions, Philosophical Magazine Series 6, 36:216, 475-476, DOI: 10.1080/14786441208635856

To link to this article: http://dx.doi.org/10.1080/14786441208635856

曲 Published online: 08 Apr 2009.

Submit your article to this journal $₫$

Џll Article views: 2

Q View related articles $\widetilde{ }$ 
LIII. On a Peculiarity of the Normal Component of the Attraction due to certain Surface Distributions. By Ganesh Prasad, M.A, D.Sc., Professor of Mathematics and Principal in the Hindu University of Benares *.

I HE object of this paper is to point out certain surface 1 distributions for each of which the component $N$ of the Newtonian attraction at a point $P$ along the normal, which passes through $\mathrm{P}$ and meets the surface at a point $O$, tends to no limit as $\mathrm{P}$ approaches $O$ along the normal. It is believed that such surface distributions have not been pointed out by any previous writer.

1. At $P$, let $N$ be equal to $N_{1}+N_{2}$, where $N_{1}$ corresponds to a small area $S$ round $O$, and $\mathrm{N}_{2}$ to the remaining part of the surface. Then it is obvious that the limit of $\mathrm{N}_{2}$ is existent: we have to consider the limit of $\mathrm{N}_{1}$. For the sake of simplicity, the surface may be taken to be regular in the neighbourhood of $\mathrm{O}$ and, consequently, $\mathrm{S}$ may be taken to be a circle of centre $O$, radius $a$, and density $\sigma$.

$$
\text { Case 1. } \sigma=\cos \log \frac{1}{r} \text {. }
$$

2. First let $\sigma=\cos \log \frac{1}{r}$, where $r$ is the distance between $O$ and the point $Q$, where the density is $\sigma$. Then it will be shown that the limit of $N_{1}$ is non-existent.

Divide the circle $\mathrm{S}$ into thin concentric rings. Then, taking the origin at $O$ and the axis of $z$ as the normal at $O$, we have

$$
\mathrm{N}_{1}=-2 \pi \int_{0}^{a} \frac{\approx \sigma r}{\left(z^{2}+r^{2}\right)^{3 / 2}}
$$

Thus we have to investigate

$$
\operatorname{Lim}_{z=0} N_{1}, \text { i.e., }-2 \pi \operatorname{Lim}_{z=0} \int_{0}^{a / z} \frac{t \sigma d t}{\left(1+t^{2}\right)^{3 / 2}},
$$

where $s t=r$.

3. Now let $\mathrm{C}$ be a sufficiontly large quantity independent of $z$. Then

$$
\begin{gathered}
\int_{0}^{a / z} \frac{t \sigma d t}{\left(1+t^{2}\right)^{3 / 2}}=\int_{0}^{c}+\int_{C}^{a / z} \frac{t \sigma d t}{\left(1+t^{2}\right)^{8 / 2}} . \\
* \text { Communicated by the Author. }
\end{gathered}
$$


476 Peculiarity of the Normal Component of Attraction.

But

Therefore

$$
\sigma=\cos \log \frac{1}{r}=\cos \left\{\log \frac{1}{z}+\log \frac{1}{t}\right\}
$$

$$
\int_{0}^{c} \frac{t \sigma d t}{\left(1+t^{2}\right)^{3 / 2}}=R \cos \left\{\log \frac{1}{z}+\gamma\right\}
$$

approximately, where

$$
\begin{aligned}
& R \cos \gamma=\int_{0}^{\infty} \frac{t \cos \log \frac{1}{t}}{\left(1+t^{2}\right)^{3 / 2}} d t, \\
& R \sin \gamma=\int_{0}^{\infty} \frac{t \sin \log \frac{1}{t}}{\left(1+t^{2}\right)^{3 / 2}} d t .
\end{aligned}
$$

Again,

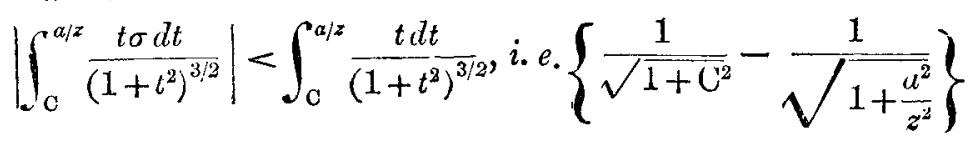

which can be made as small as we please by choosing $z$ to be sufficiently small and $\mathrm{C}$ to be sufficiently large. Thus it is proved that $\mathrm{N}_{1}$ behaves as

$$
-2 \pi R \cos \left\{\log \frac{1}{z}+\gamma\right\}
$$

as $z$ tends to 0 .

'Therefore the limit of $\mathrm{N}_{1}$, and, consequently', that of $\mathrm{N}$ are non-existent.

$$
\text { Case II. } \sigma=\cos \chi(r) \text {. }
$$

4. Take the general case in which $\sigma=\cos \chi^{\prime}(r)$, where $\operatorname{Lim} \chi(r)$ is infinite. Then the same peculiarity is noticed $x=0$ as in Case I, if

$$
\operatorname{Lim}_{r=0} \frac{\chi^{(r)}}{\log \frac{1}{r}}
$$

is zero or a finite quantity different from zero. For the proof of this statensent, see a paper of mine which will appear shortly in the 'Bulletin of the Calcutta Mathematical Suciety,' vol. ix. 